\title{
The Research and Practice of "U-Learning+CDIO" Model
}

\author{
Sun Yuejiang \\ School of Information Engineering \\ Qingdao University of Technology \\ Qingdao, China \\ 116339822@qq.com
}

\author{
Qi Chunxia,Yang Lijing \\ Department of Information Management \\ Shandong Foreign Trade Vocational College \\ Qingdao, China \\ 45153304@qq.com, 116550395@qq.com
}

\begin{abstract}
Traditional teaching modes are being changed by information technology. Ubiquitous learning (U-Learning) provides a better platform where education and information technology can be combined deeply. Based on the in-depth research on U-Learning and CDIO teaching mode, this article is written to explore and build up the "U-Learning +CDIO" teaching system, with which the teaching process of some projectpractice courses could be thoroughly analyzed, designed and reconstructed. The system proves to achieve better teaching effect and provides an effective thought and reference to solving talent cultivation problem in China.
\end{abstract}

Keywords-U-Learning; CDIO; conceive; design; implement; operate.

\section{INTRODUCTION}

The mobile internet, internet of things, cloud computing and big data technologies grows very fast and a new round of industrial revolution is happening, which results in revolution and reconstruction of the traditional manufacturing. To deal with this situation, most of countries in the world bring up their own coping strategies. The USA comes up with the strategy ADVANCED MANUFACTURING COUNTRY STRATRGICAL PLAN. Germany puts forward GERMAN INDUSTRY 4.0 STRATEGY while Britain raises BRITISH INDUSTRY2050 STRATEGY. Also China is striving to boost the strategy MADE IN CHINA 2025. The world is offering new opportunities to develop the manufacturing industry. Correspondingly, new requests for higher engineered education are produced.

As indicated in "The synopsis of National Medium-andLong-term Plan for Education Reform and Development (2010-2020)", tutors are supposed to make full use of student initiative and to develop student abilities. On 20th May 2016, the higher education conference released "the students centered education guidance ",which aims to drive universities to rebuilt the school missions of concentrating on students.so that, the quality of talent cultivation could be improved and the connotative development of higher education could be pushed .

U-learning focusing on learners and the CDIO theory are exactly meeting the requests.

This research was supported by the project "Research on training high quality applied software engineering talents based on CDIO” (project number: 2013GZ020) ", which belong to Shandong Province Education Science "12th Five-Year" Planning (key) Project ".

\section{RELATED LITERATURE}

\section{A. U-Learning}

Under the ubiquitous computing environment, U-learning has attracted great attentions. In the U-learning environment, mobile communication and augmented reality technologies make the perfect combinations of virtual environment and physical environment. It emphasizes learner center and achieve learners' study process recording, personality assessment, comments on effect and content pushing .Also, it plans, monitors and comments the cultivation of self-studying ability based on learner's model [1].

With the conception of U-learning being put forward, the research is also being explored deeply abroad. The American education professors Michael.Horn and Heather Staker[2] classified blended-learning under ubiquitous environment into three parts in their book. (1) online-studying part: blendedlearning is a standard educational item .The process of students' study is at least partly carried out through internet. During the online -learning period, students are able to decide where they study, when they study and how they study on their own initiative. (2) Learning at actual places being supervised: a part of students' studying activities are carried out with supervision at some actual places but not their families.(3)An holistic learning experience: students' learning path in some subjects or courses has to be relevant to the holistic-learning experiences. The authors emphasize the conception of standard educational item to distinguish self-learning from standard course in universities. This conception also attaches great importance to students self-control of studying, tutor's assistance as well as the combination of online-studying and face-to-face learning .The HDUL project hosted by Harvard University has obtained positive research results through mobile-leaning experiment and research on eight courses. The project named Museum with No Walls hosted by Massachusetts Institute of Technology (MIT) is innovative. Its location based and story based. It puts history and science in your hands and makes the whole globe a museum. The Japanese government has set a goal that to use ICT to build an Internet society called U-Japan where any objects and anybody can get connected whenever and wherever they want. Besides, the Mobile-learning project, M-learning project and Ulanguage-learning systems in Europe are also some practical 
explorations on blended-learning under the U-learning environment.

Chinese research of U-learning has been gradually being carried out, explored and applied widely.

Huang RongHuai listed all kinds of explanations and concluded the definition, conditions and features of Mobilelearning. He studied the key factors determining mobile learning and designed the mobile-learning-activities model[3]. Chen Ming and $\mathrm{Yu}$ ShengQuan relocated and designed the recommended system under the learning environment from the learning process situations. The recommend system provided new thought for other researchers[4].

Ye ZhengMao and Liu HuaJing explored the intelligent terminal requests for U-learning. The research indicates that the intelligent mobile terminals that are made and optimized on the base of student's willing by remote educational organization are beneficial to U-learning's development[5] .

Other related researches about U-learning and mixedlearning are the Smart-Classroom in TingHua University, the Construction Of Mobile-Learning Sources For All-Life-Long Learning in East China Normal University and some works by Liu XiaoJing ,Zhang LiangPing,Zheng Jun ,Wu Jun etc.

\section{B. CDIO Teaching Model.}

CDIO (Conceive, Design, Implement and Operate) is the latest engineering education achievement in the world. As a teaching mode which is advanced in engineered education field, it plays an important role in the engineering talent cultivation.

In Oct,2000, Edwadr F.Crawley, one of members of the American Academy of Engineering led a group from Massachusetts Institute of Technology ,Royal Institute of technology, Chalmers University of Technology ,Linkoping University and conducted a four-year research, ,exploration and practice. They concluded the latest engineering education theory and set up the CDIO international cooperation organization in 2004.Since 2000, this mode got operated in dozens of universities all over the world and have obtained great achievements. For now, scores of world-known universities in Denmark, Finland, France, South Africa, Singapore and China have joined this international organization and used the CDIO theory on teaching, which acquired great effects and be praised by society and companies.

In December 14, 2008, Ministry of Education and Shantou University carried out the CDIO Experimental Universities Conference where they ensured Shantou University, Shenzhen University, South China Agricultural University etc., 18 universities as the first batch of CDIO experimental universities, which shows CDIO mode is getting developing rapidly in our country.

Professor Cha JianZhong, from Beijing Jiaotong University, singled out seven key standards out of twelve and had a systematic and detailed introduction. He made a preliminary relation analysis among CDIO, industry -academy cooperation and internationalization. Gu Jianming and Wang Peiming think the CDIO engineering education reform, led by MIT, has emphasized on six aspects which include teaching target, teaching content, teaching method, practice teaching, teaching assessment and teacher's ability. Yan Pei and Guo Jiao, from Chongqing SanXia Institute, put forward the existing problems in software engineer teaching and offered his reformation suggestions which are based on CDIO. Doctor Jiang DaZhi from Shantou University analyzed the existing problems in Java course teaching and put forward Active Project Driven Learning based on CDIO theory. Yang YongJian from TianJing Youth Vocational College studied the CDIO standard and teaching outline and proposed the teaching mode for developing students' practical capabilities. Professor Xiao LaiYuan from Huazhong University of science and Technology brought up a practical capability cultivation model based on CDIO theory. Levels and model connotation were described.

\section{IN-DEPTH INTEGRATION OF U-LEARNING AND CDIO MODEL}

There are lots of integration and complementary possibilities between U-learning and CDIO teaching mode in Education theory, education process, education method .Ulearning is a studying method which focuses on learners' active participation and their studying assignments under Ubiquitous environment. CDIO highlights the active learning, practical ability of students and the correlation among courses [6]. The teaching way of product, process and system should be conceived, designed, implementing and operated. CDIO and Ulearning both emphasize learner-center and cultivating students' individual abilities, teaming and collaboration abilities.

Speaking of the learning method, U-learning attaches' great importance to the theory that students are central .This theory includes two aspects: personalized learning and learning based on ability. Personalized studying is fundamental to customization; its main aim is to help every individual achieve studying goals and get one-to-one tutoring from teachers instead of group tutoring .This kind of tutoring is able to get students fully benefited. Learning based on ability request students completely understand and master relevant conceptions before they continue next unit's studying .The result bought about by learning based on ability is better than learning based on time.

CDIO suggests two improvements of teaching and learning method in two basic areas: (1) Add more initiative learning and experience learning; (2) Create integrated learning experience that can help acquire science knowledge ,personal sociability as well as the constructing ability of product ,process and system .Students' studying quality could be evidently improved by active learning. .In the classroom where teacher dominate the teaching, active learning includes students questioning, group discussion, teaching responding etc. When students get in scene exchange mode, they act as a professional engineer to simulate the case, design and implement, active learning turn to experience learning. Active learning and experience learning can help students have an in-depth study, which is the precondition of innovation. Integrative learning experience means obtaining the learning experience of science knowledge, personal sociability as well as the ability to build system. These experience are gained during the process of design to implement .The goal of CDIO is to cultivate student's abilities 
in conceive, design and building models as well as solving problems. Learning method likes study based on questions, study based on cases, assignment and team cooperation can help students obtain the function of integrative learning. Figure 1 shows the methods relation and integration of U-Learning and CDIO.

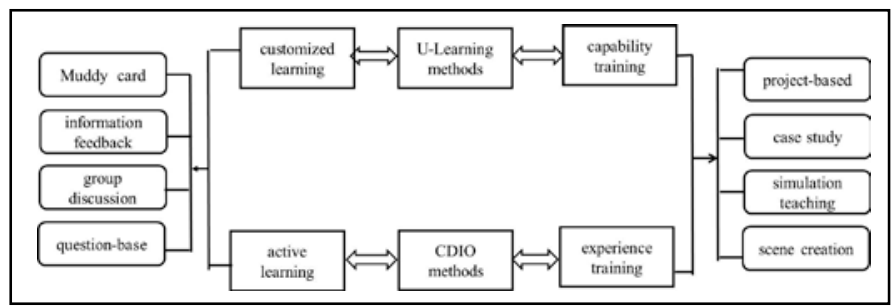

Fig. 1. Integration of U-Learning and CDIO

U-learning is a teaching mode based on education information technology. Only combine some CDIO teaching methods like case teaching method, project teaching method ,simulation teaching method, situation teaching method and question-based teaching methods, can U-learning be made fully use, inspire students' strong studying motivates and acquire better teaching effect.

\section{U-LEARNING + CDIO MODEL}

Teaching mode should be based on certain teaching theories or teaching ideas to realize specific teaching purpose. It is a teaching structure and theory frame combined with kinds of teaching elements and operational procedures. Teaching mode includes teaching thought, course design, teaching principle, teaching activity construction, teaching method etc.

The core of "U-learning +CDIO" is to combine U-learning environment and CDIO engineering education thought. In this model, kinds of teaching methods under the U-learning environment should be made full use to suit for the CDIO teaching organizing. Teaching processes and resources for CDIO would be designed to integrate U-Learning in an innovative way.

After extensive and in-depth research and investigation, we proposed a "U-learning +CDIO" Engineering Education Model, which based on the references of Robert Talbert and Zhang Jinlei, Xiao Liu Zhong, integrated the life cycle of the CDIO in engineering education. Figure 2 shows the model structure.

It should be noted that it will be rather difficult for the teaching mode to be carried out because this mode is the combination of U-learning and CDIO. So it gets more important to think how to make the organization and administration of teaching goes smoothly.

Building a unified teaching process is a meaningful thing, but building specialized teaching process according to courses' different characteristics is more significant. Now we will take practical project course as example to show the normal teaching process of "U-learning+CDIO" model.

The design of teaching process consists conceiving, designing, implementing and operating, four stages of CDIO model. At each stage, tutors divide class into three parts: before class, in the class and after class. Students should accomplish different teaching assignments under the U-learning environment.

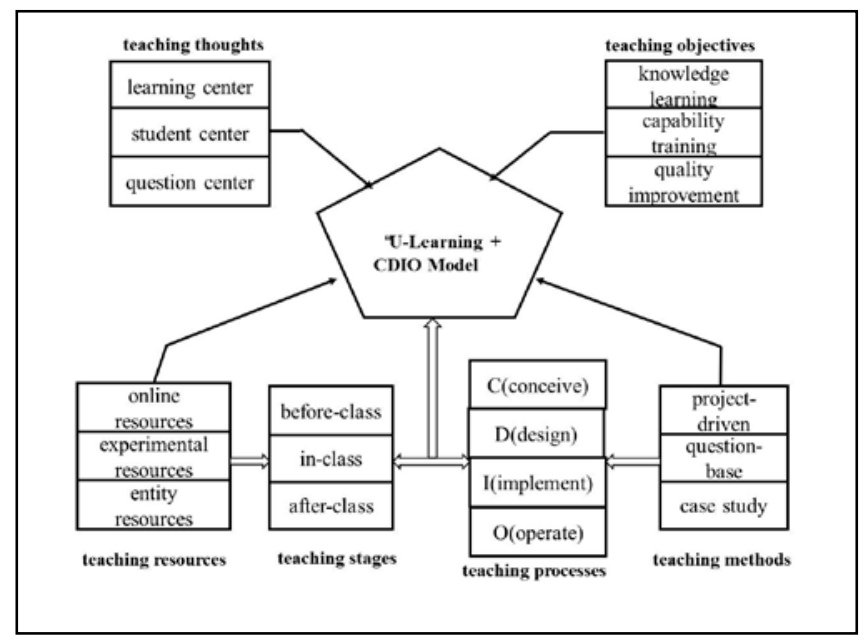

Fig. 2. U-Learning+CDIO Model

\section{A. Conceive Stage.}

In CDIO mode, Conceive means taking clients' requirement, technology, business strategy etc. into consideration and setting up system objective, system request, defining the function, conception and construction so as to lay foundation for the design, implementing and operating. Before the class, tutors develop course and record micro videos which contain courses information. In the class, tutors instruct students to analyze and discuss the question definition, possibility studying, requirement analyzing, technology selection etc. After the class, tutors release the assignment. Students fulfill the assignment and make the discussion and conclusion.

\section{B. Design Stage}

AS indicated in the teaching outline of CDIO, the design process is a series of activities in which students learn something from the design of a product, process or a system .Before the class, tutors need to record some systemdesigning videos ,then students learn through videos and have a wide discussion ;In the class ,tutors gather questions by students and answer ,also tutors need to lead and organize students to have a further discussion about whether products really meet actual needs and to assure the parts that need improving. After class, tutors release homework and tasks. Students finish homework as requested then discuss and conclude.

\section{Implement Stage}

The tasks of implementing stage include the design of the implement processes, the design of the fabrication of software and hardware, the design of the administration of the integration, testing, verification and authentication of software and hardware as well as the process of implementing.

Before class, tutors need to record some systemimplementing videos to help student prepare implementing 
knowledge they need to learn .Then student learn by themselves through the offered videos. In the class, according to students' responses, tutors answer questions specifically and lead student to discover problems and discuss. After the class, tutors release homework and assignments request, students finish homework and assignments as requested then discuss and conclude.

\section{Operate Stage}

Operating consists of tasks of how to operate, optimize, cultivate, improve, evolve, discard and administrate the products, system or the process produced by the implementing stage. Before class, tutors prepare videos for operating stage and recommend materials to students. Students learn by themselves through watching videos and looking through materials .In the class ,tutors lead students to discuss the features, problems and solutions for this stage. After class ,students finish assignments as requested and tutors give feedback and teaching comments .

\section{CONCLUSION}

The teaching mode has changed a lot because of the rapid development of education technology, which provides more possibilities for open studying in the future. People can accept kinds of digital education in relaxing spaces at more leisure time. In this article, a "U-learning+CDIO" teaching mode was built up based on U-learning and CDIO research, which offers a new thought for the talent cultivation in engineering area.

\section{ACKNOWLEDGMENT}

Thanks to my project team and colleagues who have attributed so much for the research and thanks to the members of project management department.

This research was supported by the project "Research on training high quality applied software engineering talents based on CDIO” (project number: 2013GZ020) ", which belong to Shandong Province Education Science "12th Five-Year" Planning (key) Project ".

\section{REFERENCES}

[1] Lin Xiuyu. Study on the Effect of Micro Course Learning Mode in the Ubiquitous Learning Environment.China Educational Technology. 2014.6:18-22

[2] Michael B.Horn,Heather Staker,Nie Fenghua, Xu Tieing translate. Blended UsingDisruptive Innovation to Improve Schools.Beijing:China Machine Press.2015.9.

[3] Huang Ronghuai,Wang Xiaocheng, Li Yushun. Towards a Theory of Mobile Learning Activity Design.Journal of Distance Education. 2009.1:3-7.

[4] Chen Min, Yu Shengquan. Design of the recommendation system based on learning process under Ubiquitous Learning Environment. EEducation Research.2015.4:76-89.

[5] Ye Zhengmao, Liu Huajin. Analysis of Mobile Terminal based on ULearning. Research in Higher Education of Engineering.2015.6:1-6.

[6] Edward F.Crawley,Johan Malmqvist etc,Gu Peihua translate.Rethinking Engineering Education:The CDIO Approach.Beijing:Cchina Higher Education Press.2010.1. 